\title{
Microbiology of brewing production - bacteria of the order Enterobacterales and culture methods for their detection
}

\author{
Petra Kubizniaková*, Martina Brožová, Kateřina Štulíková, Eva Vontrobová, Katarína Hanzalíková, \\ Dagmar Matoulková
}

Research Institute of Brewing and Malting, Plc., Lípová 15, 12000 Prague, Czech Republic

*corresponding author: kubizniakova@beerresearch.cz

\begin{abstract}
The growth of 7 strains belonging to the order of Enterobacterales, represented by the species of Citrobacter freundii, Enterobacter cloacae, Escherichia coli, Klebsiella oxytoca, Obesumbacterium proteus, Rahnella aquatilis, Raoultella terrigena, Serratia marcescens and Shimwellia pseudoproteus, was monitored on selected cultivation media. Three types of agars - Endo, MacConkey and Chromocult Coliform agar together with two incubation temperatures of 28 and $37^{\circ} \mathrm{C}$ were tested under aerobic conditions. The aim of the study was to detect such essential enterobacteria harmful to beer that cannot be proven at $37^{\circ} \mathrm{C}$, which is the temperature usually used in operational laboratories in breweries. Our results showed that most of the tested strains of enterobacteria were able to grow at $28^{\circ} \mathrm{C}$ on all selected types of agar. The exception was just the representatives detection of which is problematic at $37^{\circ} \mathrm{C}$. Nevertheless, a little or no growth was always observed on just one of the tested media.
\end{abstract}

Keys words: enterobacteria, facultative-anaerobic bacteria, Klebsiella, coliform bacteria, wort contamination, Obesumbacterium, N-nitrosamines, Rahnella, Serratia, Shimwellia

\section{Introduction}

This article follows a review paper entitled Microbiology of brewery production - bacteria of the order of Enterobacterales (Matoulková et al., 2018). The Enterobacterales order contains 7 families with more than 40 bacterial genera that are isolated from diverse types of environments. Particularly members of Shimwellia, Obesumbacterium, Rahnella, Citrobacter, Klebsiella, Raoultella, Serratia and Enterobacter genera were found in breweries. On the other hand, pathogenic species, including Escherichia coli, have not been detected in breweries (Van Vuuren and Priest, 2003).

Mainly due to the sensitivity of enterobacteria to ethanol and acidic $\mathrm{pH}$, their growth and ability to multiply in the finished beer is minimal and they occur mainly as a contamination of production yeast.

Contaminated water or unsatisfactory hygienic condition of surfaces and equipment (e.g. leakage of pipe connection) represent other usual sources of enterobacteria (Vaughan et al., 2005). These bacteria are harmful since they produce undesirable sensory substances (e.g. diacetyl and dimethyl sulphide) at the beginning of the main fermentation. Moreover, some species are involved in the formation of carcinogenic $N$-nitrosamines (Boulton and Quain, 2001).

Shimwellia pseudoproteus and Rahnella aquatilis present an increased risk as they can repeatedly penetrate into a new batch of wort as contaminants of pitching yeast and therefore they are able to damage several batches of beer in a row (Bokulich and Bamforth, 2013). The damaged beer then shows a sweet, honey, fruity to vegetable and even fecal character (Jespersen and Jakobsen, 1996; Briggs et al., 2004).

The detection of enterobacteria in operational brewing laboratories is a routine procedure that is carried out mostly on MacConkey agar or chromogenic media at $37^{\circ} \mathrm{C}$. 
In this study, we compared the growth of selected species of enterobacteria on several types of cultivation agars - Endo, MacConkey and Chromocult Coliform agar at $28^{\circ} \mathrm{C}$ (the temperature recommended for incubation of some Shimwellia, Obesumbacterium and Rahnella species) and $37{ }^{\circ} \mathrm{C}$ (the temperature recommended for incubation of some Citrobacter, Klebsiella, Raoultella and Serratia).

\section{Material and Methods}

\subsection{Cultivation media}

- Plate Count agar (PCA): 22.5 g of PCA powder (Merck) was dissolved in $1000 \mathrm{~mL}$ of distilled water and sterilized at $121^{\circ} \mathrm{C}$ for 20 minutes.

- Nutrient agar (NA): 20 g of NA powder (Merck) was dissolved in $1000 \mathrm{~mL}$ of distilled water and sterilized at $121^{\circ} \mathrm{C}$ for 20 minutes.

- Endo agar: $39 \mathrm{~g}$ of Endo agar powder (Merck) was dissolved in $1000 \mathrm{~mL}$ of distilled water and sterilized at $121{ }^{\circ} \mathrm{C}$ for 20 minutes.

- MacConkey agar: $50 \mathrm{~g}$ of MacConkey agar powder (Merck) was dissolved in $1000 \mathrm{~mL}$ of distilled water and sterilized at $121^{\circ} \mathrm{C}$ for 20 minutes.

- Chromocult Coliform agar: $26.5 \mathrm{~g}$ of Coliform agar powder (Merck) as dissolved in $1000 \mathrm{~mL}$ of distilled water and sterilized at $121^{\circ} \mathrm{C}$ for 20 minutes.

\subsection{Microorganisms and cultivation conditions}

The used bacterial strains came from the following col- lections: Czech Collection of Microorganisms (CCM), the Collection of Brewing Microorganisms (RIBM) and the German Collection of Microorganisms and Cell Cultures (DSMZ). The list of strains, their marks and origins is given in Table 1. The strains were incubated under aerobic conditions on PCA agar at $28^{\circ} \mathrm{C}$ for 48 hours before inoculation on experimental media.

\subsection{Preparation of bacterial suspension and cultivation conditions}

Bacterial suspensions were prepared by stiring 1 colony obtained from agar plate into a sterile physiological solution. The concentration of resulting cell was approximately $3 \times 10^{8}$ cells $/ \mathrm{mL}$. The suspensions were diluted in order to grow a countable number of colonies on Petri dishes (i.e. 10-50). Their incubation was maintained under aerobic conditions at 28 and $37^{\circ} \mathrm{C}$ for 48 hours.

\section{Results and discussion}

All bacterial strains grew on basic culture media (NA and PCA) and showed no differences in the appearance of their colonies. This is demonstrated in Figure 1., where the colonies of $C$. freundii CCM 7187 on NA are present. Regular, flat to slightly convex smooth colonies with a glossy surface and white to slightly cream colour were formed. A similar description of the colonies is reported by such authors as Holt et al. (1994), Back (2005) or Cosmas et al. (2016).

Table 1 The list of tested strains, their designation and origin

\begin{tabular}{|c|c|c|c|}
\hline Bacterial species & Strain* & Origin & $\begin{array}{l}\text { Optimal growth } \\
\text { temperature }\end{array}$ \\
\hline \multirow{2}{*}{ Citrobacter freundii } & CCM 4475 & Frozen carrot & $37^{\circ} \mathrm{C}$ \\
\hline & CCM 7187 & Clinical material & $37^{\circ} \mathrm{C}$ \\
\hline Enterobacter cloacae & CCM 7931 & Brewery operation - water & $30^{\circ} \mathrm{C}$ \\
\hline \multirow{2}{*}{ Escherichia coli } & CCM 7395 & Food sample & $30^{\circ} \mathrm{C}$ \\
\hline & RIBM CH1 & Brewery operation - water & $30^{\circ} \mathrm{C}$ \\
\hline Klebsiella oxytoca & CCM 3565 & Drinking water & $37^{\circ} \mathrm{C}$ \\
\hline \multirow{2}{*}{ Obesumbacterium proteus } & CCM 2806 & Brewer's top fermenting yeast & $30^{\circ} \mathrm{C}$ \\
\hline & DSM 2777 & Brewer's top fermenting yeast & $30^{\circ} \mathrm{C}$ \\
\hline Rahnella aquatilis & CCM 4086 & Salt & $30^{\circ} \mathrm{C}$ \\
\hline Raoultella terrigena & CCM 3568 & Drinking water & $37^{\circ} \mathrm{C}$ \\
\hline \multirow{2}{*}{ Serratia marcescens } & $\mathrm{CCM} 303^{\top}$ & Water & $37^{\circ} \mathrm{C}$ \\
\hline & CCM 8587 & Karst water & $30^{\circ} \mathrm{C}$ \\
\hline \multirow{2}{*}{ Shimwellia pseudoproteus } & DSM 3038' & Brewer's top fermenting yeast & $30^{\circ} \mathrm{C}$ \\
\hline & DSM 22121 & Brewer's top fermenting yeast & $30^{\circ} \mathrm{C}$ \\
\hline
\end{tabular}




\subsection{The growth of selected enterobacteria on Endo agar}

Because of the toxicity and low stability of fuchsin, Endo agar is used only to a limited extent for detection of coliform bacteria. The selectivity of Endo agar is determined by the content of basic fuchsin (decolorized with sulphite), with the carbon substrate being lactose. The colour of colonies makes it possible to distinguish between lactose-positive (pink or red colonies possibly with a greenish metallic lustre) and lactose-negative (colourless and cream colonies) bacteria. In our case, pink and red colonies with a metallic lustre or without any lustre were observed on Endo agar (Figure 2).



Figure 2 Morphology of enterobacteria colonies on Endo agar A - E. cloaceae CCM $7931 \quad$ B - E. coli RIBM CH1

Colonies of $C$. freundii CCM 4475, E. coli RIBM CH1 and $K$. oxytoca CCM 3565 were red with a metallic lustre. Red colonies without a metallic lustre belonged to the strains of E. coli CCM 7395, Enterobacter cloaceae CCM 7931, R. terrigena CCM 3568 and S pseudoproteus DSM 22121. Various sources refer to a description of E. coli colonies: for instance Niemi et al. (2001) described the growth of $E$. coli as red colonies with a metallic lustre, while Back (2005) reported glossy and pink-red colonies.

Both strains of 0 . proteus (CCM 2806 and DSM 2777 ) as well as the strain of $S$. marcescens CCM 8587 provided pale pink colonies. Other bacteria grew in the form of pink colonies. S. pseudoproteus DSM 3038 formed red metallic colonies on Endo agar. Endo agar was the only test medium on which the potentially risky bacteria of $S$. pseudoproteus DSM $3038^{\mathrm{T}}$ and R. aquatilis CCM 4086 were growing at $37^{\circ} \mathrm{C}$. The presence of enterobacterial colonies on Endo agar is represented by E. cloaceae CCM 7931 (Figure 2A) and E. coli RIBM CH1 (Figure 2B).

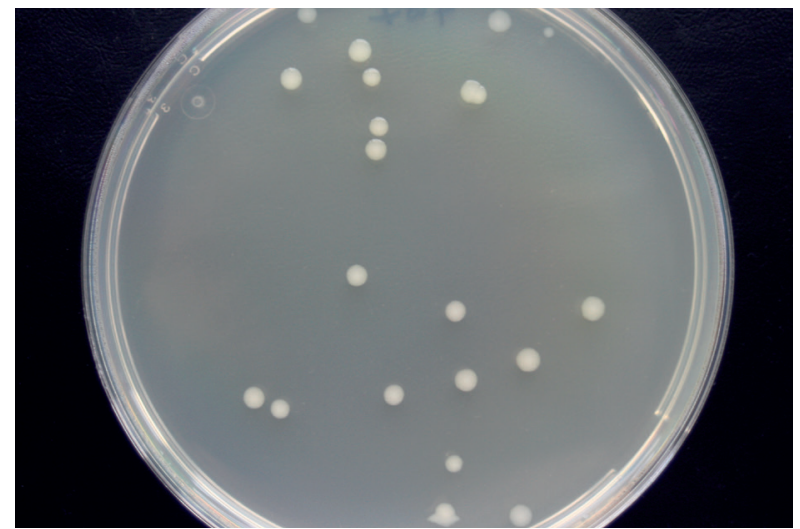

Figure 1 Morphology of C. freundii CCM 7187 colonies on nutrient agar

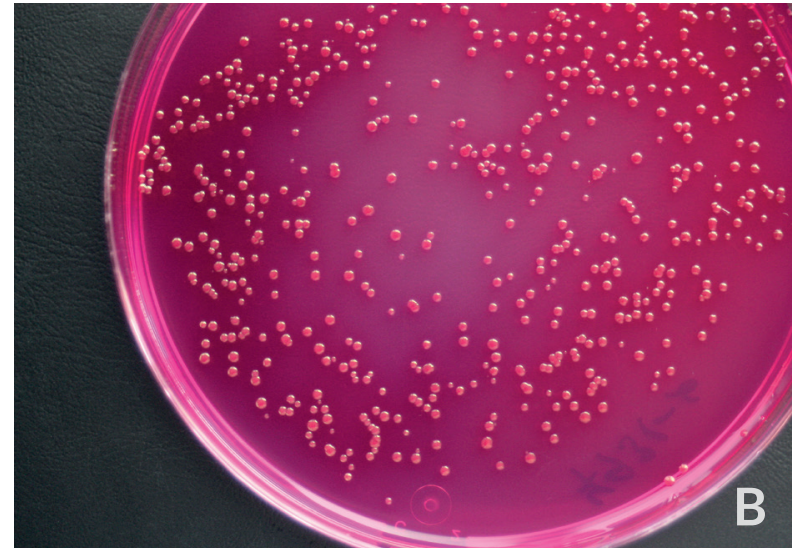

\subsection{The growth of selected enterobacteria on MacConkey agar}

Endo agar was gradually replaced by MacConkey medium especially due to the toxicity of fuchsin and because of numerous aspects from the field of clinical microbiology. MacConkey agar contains lactose as a carbon source and a neutral red as a $\mathrm{pH}$ indicator. The medium enables detection of lactose-positive (coliform) bacteria, which grow on agar plates in the form of pink colonies without changing the colour of the culture medium. Lactose-negative bacteria (e.g. Obesumbacterium, Shimwellia) form cream-coloured colonies on MacConkey agar and they discolour the medium into light yellow to ochre. Gram-positive bacteria are inhibited by crystal violet and bile salts (Finney et al., 2003). Bacterial growth on MacConkey Agar is documented in Figure 3.

Lactose-positive representatives of $C$. freundii CCM 4475, E. cloacae CCM 7931, E. coli CCM 7395 (Figure 3A), K. oxycota CCM 3565 (Figure 3B) and S. marcescens CCM $303^{\mathrm{T}}$ (Figure 3D) formed pink colonies without changing the colour of the medium at both incubation 
temperatures. An exception was the strain of $R$. aquatilis CCM 4086, which did not grow at $37{ }^{\circ} \mathrm{C}$ at all. This finding corresponds to the basic characteristics of the genus - the temperature optimum for most representatives is between $25-35^{\circ} \mathrm{C}$; at $37^{\circ} \mathrm{C}$ they grow significantly slowly (Kämpfer, 2015).

Lactose-negative bacteria of O. proteus DSM 2777 and S. pseudoproteus DSM 3038 ${ }^{\mathrm{T}}$, formed cream coloured colonies at $28{ }^{\circ} \mathrm{C}$ and the medium is discoloured into light yellow to ochre as a result of their metabolism (Figure $3 \mathrm{C}$ ). They formed no or only very poorly observable colonies at $37^{\circ} \mathrm{C}$.

The temperature optimum for most representatives is between 25 and $32{ }^{\circ} \mathrm{C} .37^{\circ} \mathrm{C}$ is the temperature commonly used for incubation of enterobacteria in brewing laboratories. It should be noted that the bacteria grow substantially more slowly at this temperature (Sedláček, 2007). Thus, our results show a risk that detection of harmful bacteria belonging to the genera of Rahnella or Shimwellia in beer will fail during cultivation on MacConkey agar at the recommended temperature of $37^{\circ} \mathrm{C}$.

\subsection{The growth of selected enterobacteria on Chromocult Coliform agar}

Chromocult Coliform agar was developed so that it could detect the total number of coliform bacteria together with the number of $E$. coli in one sample simultaneously. The medium contains two chromogenic substrates: Salmon-GAL to detect $\beta$-D-galactosidase (an enzyme that breaks down lactose into galactose and glucose) and X-glucuronide to detect presence of $\beta$-D-glucuronidase enzyme. Coliform bacteria show $\beta$-D-galactosidase activity. Although E. coli belongs to coliform bacteria, it can be distinguished from other coliform bacteria in the same agar plate due to $\beta$-D-glucuronidase activity. The growth of Gram-positive bacteria/organisms is inhibited by tergitol-7. Coliform bacteria grow on Chromocult Coliform agar in the form of pink to red colonies, while E. coli forms dark blue to purple colonies. The accompanying microflora grows in the form of colourless colonies (Finney et al., 2003). In our study the formation of pinkish or light pink colonies was observed in cases of Serratia, Enterobacter, Klebsiella, Citrobacter, Rahnella and Shimwellia. Detailed description for E. cloacae CCM 7931 is given in Figure 4A, for K. oxytoca CCM 3565 in Figure 4C. O. proteus strains DSM 2777 are elaborated in Figure 4D. S. pseudoproteus DSM 22121 grew as pink-purple colonies and both E. coli strains formed dark blue-violet colonies represented by E. coli strain RIBM CH1 shown in Figure 4B. Pink staining of E. cloacae and colonies of Klebsiella members, as well as blue-violet colour in E. coli have also been reported for example by Niemi et al. (2001).

\subsection{The effect of incubation temperature on selected enterobacteria growth}

The results of the growth of enterobacteria on various culture media at 28 and $37^{\circ} \mathrm{C}$ are presented in Table 2 . As for the temperature of $28{ }^{\circ} \mathrm{C}$ almost all tested bacterial strains grew on all types of media during this temperature. There are only two exceptions: the first being the strain of $O$. proteus CCM 2806 which generally grew more slowly and it did not grow at all on MacConkey and Chromocult Coliform agar soils. The other is S. pseudoproteus DSM 22121 which also did not grow on MacConkey agar. If we refer to the temperature of $37^{\circ} \mathrm{C}$, the strain of 0 . proteus CCM 2806 did not grow on any of the used medium, R. aquatilis CCM 4086 as well as S. pseudoproteus DSM $3038^{\mathrm{T}}$ formed colonies only on Endo agar, $R$. aquatilis grew in no other culture media apart from Endo agar and Shimwellia did not grow at all or very weakly in any presented media.
Figure 3 Morphology of enterobacteria colonies on MacConkey agar A - E.coli CCM 7395 C - O. proteus DSM 2777
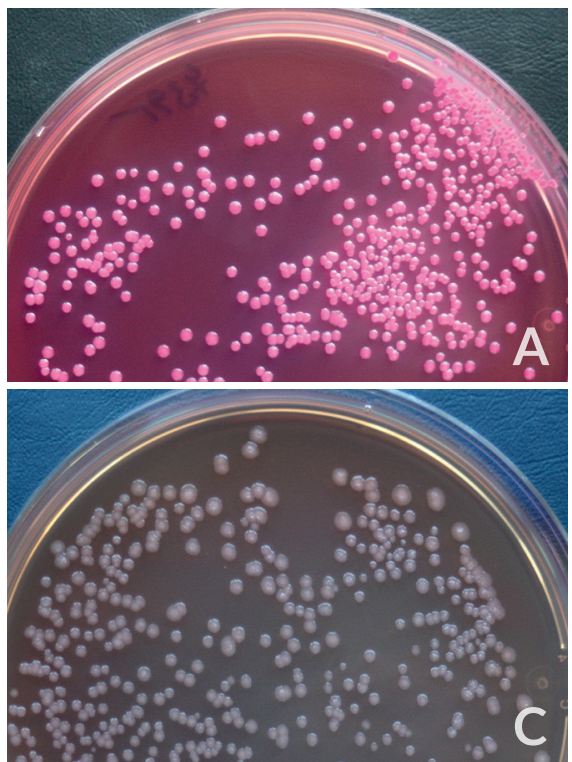

B - K. oxytoca CCM 3565

D - S. marcescens CCM 303
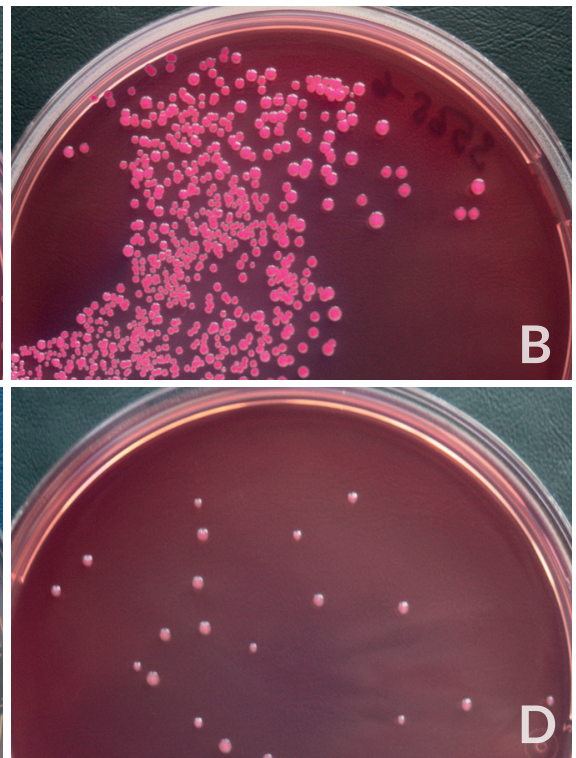
The presented results are consistent with the basic characteristics of the species. The temperature optimum of most members of the genera Obesumbacterium and Shimwellia is in the range of $25-32{ }^{\circ} \mathrm{C}$, in the genus Rahnella $25-35{ }^{\circ} \mathrm{C}$. At $37^{\circ} \mathrm{C}$, these bacteria grow significantly more slowly (Sedláček, 2007). The cultivation of enterobacteria in operational brewing laboratories takes place as standard at the temperature of $37^{\circ} \mathrm{C}$ (Analytica EBC, 2011). Thus, the most risky taxa, such as S. pseudoproteus ("O. proteus") and $R$. aquatilis, may not be detected during routine microbiological checks.

\section{Conclusion}

The presence of enterobacteria in samples that were taken in several breweries indicates deteriorating hygienic conditions and low levels of sanitation during the operation. Detection of enterobacteria is usually performed routinely in operational brewing laboratories. For diagnosis of en-
Figure 4 Morphology of enterobacteria colonies on Chromocult Coliform agar

A - E. cloaceae CCM $7931 \quad$ B - E. coli RIBM CH1

C - K. oxytoca CCM $3565 \quad$ D - O. proteus DSM 2777
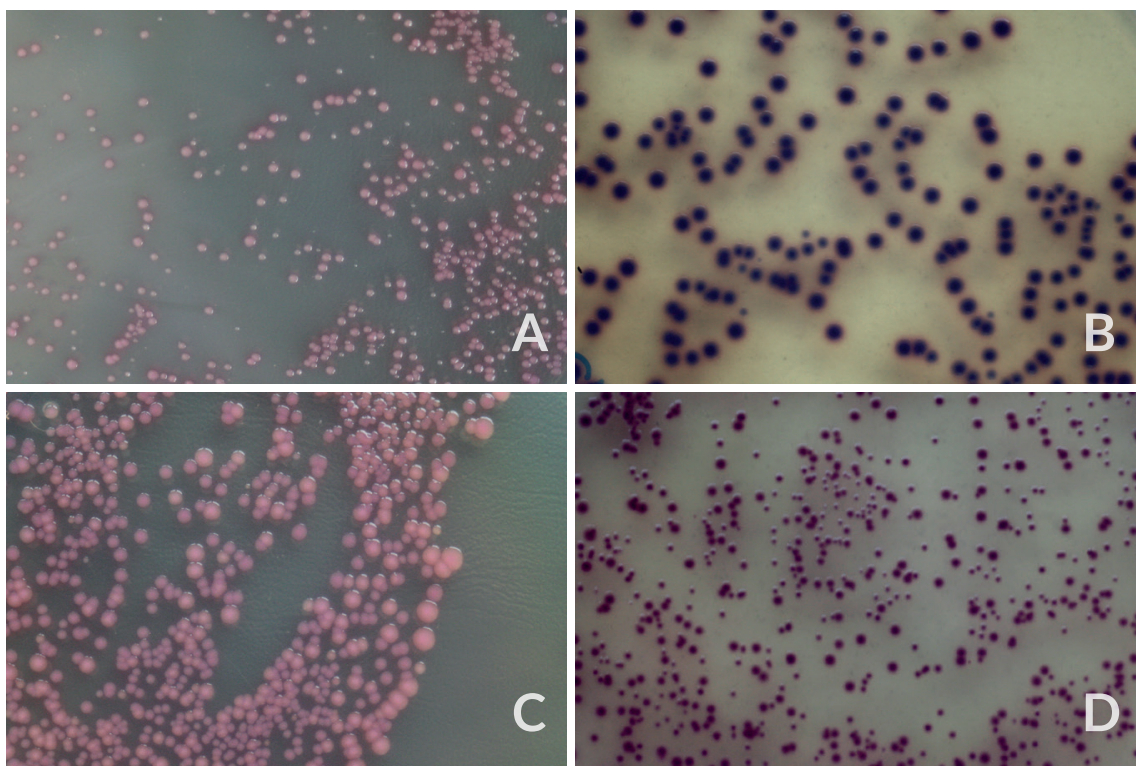

terobacteria, usually MacConkey agar or chromogenic media are used and the cultivation is carried at $37^{\circ} \mathrm{C}$. In our study we compared cultivations on different media - Endo agar, MacConkey agar, and Chromocult Coliform agar at two incubation temperatures of $28{ }^{\circ} \mathrm{C}$ and the commonly used $37{ }^{\circ} \mathrm{C}$ in order to monitor the growth character of enterobacteria. We proved that the cultivation at the above-mentioned $37^{\circ} \mathrm{C}$ led to a slower growth or no growth at all in the case of the strains Shimwellia pseudoproteus ("O. proteus")

Table 2 An overview of the enterobacteria growth at 28 and $37^{\circ} \mathrm{C}$

\begin{tabular}{|c|c|c|c|c|c|c|}
\hline \multirow{2}{*}{ Species } & \multirow{2}{*}{ Strain } & \multicolumn{5}{|c|}{ Culture medium $28^{\circ} \mathrm{C} / 37^{\circ} \mathrm{C}$} \\
\hline & & NA & PCA & Coli & Endo & Mac \\
\hline \multirow{2}{*}{ Citrobacter freundii } & CCM 4475 & $+1+$ & $+/+$ & $+/+$ & $+/+$ & $+/+$ \\
\hline & CCM 7187 & $+1+$ & $+1+$ & $+1+$ & $+1+$ & $+/+$ \\
\hline Enterobacter cloacae & CCM 7931 & $+/+$ & $+/+$ & $+/+$ & $+1+$ & $+/+$ \\
\hline \multirow{2}{*}{ Escherichia coli } & CCM 7395 & $+/+$ & $+1+$ & $+/+$ & $+1+$ & $+/+$ \\
\hline & RIBM CH1 & $+/+$ & $+/+$ & $+/+$ & $+1+$ & $+/+$ \\
\hline Klebsiella oxytoca & CCM 3565 & $+1+$ & $+1+$ & $+/+$ & $+1+$ & $+/+$ \\
\hline \multirow{2}{*}{ Obesumbacterium proteus } & CCM 2806 & $+/-$ & $+/-$ & $-/-$ & $+/-$ & $-/-$ \\
\hline & DSM 2777 & $+1+$ & $+1+$ & $+/+$ & $\sim / \sim$ & $+/ \sim$ \\
\hline Rahnella aquatilis & CCM 4086 & $+/-$ & $+1-$ & $+1-$ & $+/+$ & $+1-$ \\
\hline Raoultella terrigena & CCM 3568 & $+1+$ & $+1+$ & $+/+$ & $+1+$ & $+/+$ \\
\hline \multirow{2}{*}{ Serratia marcescens } & CCM $303^{\top}$ & $+1+$ & $+1+$ & $+1+$ & $+1+$ & $+/+$ \\
\hline & CCM 8587 & $+/+$ & $+/+$ & $+/+$ & $+/+$ & $+/+$ \\
\hline \multirow{2}{*}{ Shimwellia pseudoproteus } & DSM 3038' & $+/ \sim$ & $+1-$ & $+1-$ & $+/+$ & $+/ \sim$ \\
\hline & DSM 22121 & $+/ \sim$ & $+/ \sim$ & $+/-$ & $+/ \sim$ & $-/ \sim$ \\
\hline
\end{tabular}


and Rahnella aquatilis (i.e. the taxa with the greatest potential of harmfulness from the point of view of microbiological control in a brewery). Thus, in laboratories that use only the incubation temperature of $37^{\circ} \mathrm{C}$ for the detection of enterobacteria, some harmful strains may not be detected.

\section{Acknowledgments}

Results were obtained under financial support from the Ministry of Agriculture CR (R01918) and the Ministry of Education, Youth and Sports of the Czech Republic (L01312).

\section{References}

EBC 4.2.4.1 (2011). Enterobacteriaceae, In: EBC Analysis Committee-Nürnberg (Ed.), Analytica EBC, Hans Carl Getränke Fachverlag, Chap.4.2.4.1.

EBC 4.4.2 (2011). Escherichia coli and coliform bacteria, In: EBC Analysis Committee-Nürnberg (Ed.), Analytica EBC, Hans Carl Getränke Fachverlag, Chap. 4.4.2.

Back, W. (2006). Brewery. In: Back W. (Ed.), Colour atlas and handbook of beverage biology. Verlag Hans Carl, Nürnberg, Germany, pp.10-112. ISBN-10: 3418007996/ISBN-13: 9783418007991

Bokulich, N.A., Bamforth, C.W. (2013). The microbiology of malting and brewing. Microbiology and Molecular Biology Review, 77, 157-172. https://doi.org/10.1128/MMBR.00060-12

Boulton, C., Quain, D. (2001). Brewing yeast and fermentation. 1st edition, Blackwell Science Ltd., London, England. Online ISBN: 9780470999417

Briggs, D.E., Boulton, C.A., Brookes, P.A., Stevens, R. (2004). Brewing: science and practice. Woodhead Publishing, Cambridge UK/CRC Press, Boca Raton, Florida, USA, 881 pp. ISBN: 0-8493-2547-1

Cosmas, L.L., Atong, M., Poili, E. (2016). Preliminary studies towards identification of ginger wilt disease in Sabah, Malaysia. Pertanika Journal of Tropical Agricultural Science, 39(3): 373-380. ISSN: 1511-3701. Available from: https://www.researchgate.net/publication/305656011_Preliminary_Studies_towards_Identification_of_ Ginger_Wilt_Disease_in_Sabah_Malaysia
Farmer, III, J.J., Boatwright, K.D., Janda, J.M. (2007). Enterobacteriaceae: introduction and identification. In: Murray P. P. (Ed.), Manual of clinical microbiology 9th edition. ASM Press, Washington, D.C. ISBN: 15558137129781555813710

Finney, M., Smullen, J., Foster, H.A., Brokx, S., Storey, D.M. (2003). Evaluation of Chromocult coliform agar for the detection and enumeration of Enterobacteriaceae from faecal samples from healthy subjects. Journal of Microbiological Methods, 54, 353-358. https://doi. org/10.1016/S0167-7012(03)00068-X

Holt, J.G., Krieg, N.R., Sneath, P.H.A., Staley, J.T., Williams, S.T. (1994). Group 5: Facultatively anaerobic gram-negative rods. In: Holt, J.G., Krieg, N.R., Sneath, P.H.A., Staley, J.T., Williams, S.T. (Eds.), Bergey's Manual of Determinative Bacteriology 9th edition. Williams \& Wilkins, Baltimore, MD. ISBN-10: 9780683006032 / ISBN-13: 978-0683006032

Jespersen, L., Jakobsen, M. (1996). Specific spoilage organisms in breweries and laboratory media for their detection. International Journal of Food Microbiology, 33, 139-155. https://doi.org/10.1016/01681605(96)01154-3

Kämpfer, P. (2015). Rahnella. In: Whitman, W.B. (Ed.), Bergey's Manual of Systematics of Archaea and Bacteria. John Wiley \& Sons, Inc., in association with Bergey's Manual Trust. https://doi. org/10.1002/9781118960608.gbm01164

Matoulková, D., Vontrobová, E., Brožová, M., Kubizniaková, P. (2018). Microbiology of brewery production - bacteria of the order Enterobacterales. Kvasny prumysl, 64, 161-166. https://doi.org/10.18832/ kp201824

Niemi, R.M., Heikkilä, M.P., Lahti, K., Kalso, S., Niemelä, S.I. (2001). Comparison of methods for determining the numbers and species distribution of coliform bacteria in well water samples. Journal of Applied Microbiology, 90, 850-858. https://doi.org/10.1046/ j.1365-2672.2001.01314.x

Sedláček, I. (2007). Taxonomie prokaryot. 1. vydání, Masarykova univerzita, Brno. ISBN: 80-210-4207-9

Vaughan, A., O'Sullivan, T., van Sinderen, D. (2005). Enhancing the microbiological stability of malt and beer - a review. Journal of the Institute of Brewing, 111,355-371. https://doi.org/10.1002/j.2050-0416.2005. tb00221.x

Van Vuuren, H.J.J., Priest, F.G. (2003). Gram-negative brewery bacteria. In: Priest, F. G. and Campbell, I. (Eds.), Brewing Microbiology, Springer US, 219-245. ISBN 978-1-4419-9250-5 